\title{
Which Reward Should I Choose? Preliminary Evidence for the Middle- Option Bias in Reward-Based Crowdfunding
}

\author{
Alexander Simons \\ University of Liechtenstein \\ alexander.simons@uni.li
}

\author{
Markus Weinmann \\ University of Liechtenstein \\ markus.weinmann@uni.li
}

\author{
Matthias Tietz \\ University of Liechtenstein \\ matthias.tietz@uni.li
}

\author{
Jan vom Brocke \\ University of Liechtenstein \\ jan.vom.brocke@uni.li
}

\begin{abstract}
Crowdfunding has become an important research area, but we know little about how rewards influence fundraising success. This research-in-progress studies reward-based crowdfunding through a behavioraleconomics lens. We draw on dual-process theory and provide preliminary evidence for the middle-option bias in crowdfunding. Two empirical studies in a simple, controlled environment confirm the significance of the middle-option bias, both for varying numbers of donation options and for varying price ranges. Since our findings suggest that the positioning of rewards in a menu of rewards can influence support behavior and how much money project creators collect, they can inform the design of crowdfunding projects. Our future research will develop a mock crowdfunding website to study the middle-option bias in a more realistic environment.
\end{abstract}

\section{Introduction}

Crowdfunding is the practice of collecting small amounts of money for entrepreneurial, charitable, or creative projects from a large number of people, typically moderated by Internet websites [3]. Rewardbased crowdfunding, implemented by popular websites like Kickstarter and Indiegogo, has become particularly common on the Internet [37]. A distinct feature of reward-based crowdfunding websites is that, while backers do not receive anything financial (e.g., shares or interest) in return for their money, they can receive non-monetary rewards, such as the chance to prepurchase the product or to receive tokens of appreciation (e.g., autographs or meet-and-greets) [7].

With its broad adoption in practice, the rewardbased model of crowdfunding is receiving increasing attention from researchers [32]. In particular, researchers have studied what determines fundraising success, including project design and description, networking effects and communication behavior, and the project creators' experience and background [e.g., 22, 30, 31, 37]. Still, crowdfunding research remains in its infan- cy, and several research gaps remain [32]. In particular, with few exceptions [e.g., 26, 51], the design of reward menus has seldom been studied. While some researchers have found that the number of rewards influences fundraising success [e.g., 31], the selection of reward tiers and the determination of the donation amounts to which they are connected have not been studied in sufficient depth.

Against this background, this research-in-progress studies the design of reward menus through a behavioral-economics lens. We present preliminary results from two empirical studies - an experimental study and an observational study - and hypothesize that the positioning of rewards in a reward menu influences backers' decisions. Specifically, we provide preliminary evidence for the middle-option bias $[16,49]$ in crowdfunding, so our results suggest that project creators may have a way to position rewards that collects more money and reaches funding targets more quickly. This early-stage research focuses on internal validity by isolating the middle-option bias in a simple, controlled environment, and our future research will test the middle-option bias in a more realistic environment to establish ecological validity.

Section 2 provides background on reward-based crowdfunding, and Section 3 reviews related work. Section 4 explains the middle-option bias and presents the paper's hypotheses. Section 5 explains the overall research design, and Sections 6 and 7 present the results from the two empirical studies. Section 8 discusses implications and limitations and provides an outlook on future research.

\section{Reward-based crowdfunding}

Crowdfunding is big business. The crowdfunding industry grew from $\$ 6.1$ billion in 2013 to $\$ 16.2$ billion in 2014 and to an estimated $\$ 34.4$ billion in 2015 [36]. Many thousands of crowdfunding projects have been funded successfully, and over one hundred of them have raised more than $\$ 1$ million [50]. An ongoing crowdfunding initiative for the video game Star Citizen had collected more than $\$ 124.1$ million funds at last 
count [43]. With its broad success in practice, crowdfunding has become a hot research topic in the area of crowd science [38], triggering research in disciplines like entrepreneurship, management, finance, marketing, and information systems [10]. Even so, a common definition of crowdfunding has not yet emerged, although several researchers have offered definitions and conceptualizations [11]. Many researchers have discussed the meaning of crowdfunding based on the closely related term "crowdsourcing" [1], which refers to outsourcing jobs or tasks to a large, often anonymous group of people (the "crowd") in the form of an open call [25]. Crowdsourcing often follows the idea of the "wisdom of the crowd," according to which collective ideas and judgments are often as good as, or even better, than those of single individuals [44]. Against this background, crowdfunding can be understood as a form of micro-task crowdsourcing that collects financial instead of intellectual contributions [39].

The idea of collecting small amounts of money from a large number of people for funding projects and ventures is not new, similar funding approaches have been used for centuries; for example, the Statue of Liberty was funded by small donations from American and French people [32]. That crowdfunding has recently gained so much momentum can be attributed to the emergence of the Internet, which allows broader participation than ever before [11].

A variety of crowdfunding websites populate the Internet, serving as intermediaries between project creators and the crowd and managing most of the activities involved in the crowdfunding process [24]. Crowdfunding websites usually follow one of four models that are distinguished based on what backers receive for their financial contributions [9]: In donation-based crowdfunding (e.g., ammado), which is typically used to fund charity projects, backers do not receive anything tangible in return for their money [e.g., 13]. In lending-based crowdfunding (e.g., Kiva), backers provide loans and usually receive interest in return, so this model is most common for microfinance and private credits [e.g., 14]. In equity-based crowdfunding (e.g., Crowdcube), backers receive shares, dividends or voting rights for their money, so this model relies on traditional investment mechanisms and is typically used for small-business funding [e.g., 12]. The fourth model is reward-based crowdfunding (e.g., Kickstarter), which is in the focus of this paper.

In reward-based crowdfunding, which has become common in the creative industries [2], backers receive something non-financial, whether material or immaterial, in return for their money - that is, a reward. For example, a film-funding campaign typically involves material rewards like the chance to pre-purchase the Blu-ray or DVD, and immaterial rewards like film roles, visits to the film set, or thanks in the film credits. Reward-based crowdfunding can follow either of two basic principles: "all-or-nothing" and "keep-it-all" [17]. Projects that follow the all-or-nothing principle are funded only if a predefined funding goal is reached within a set timeframe; otherwise, the backers get their money back and the project creators receive nothing [24]. In the keep-it-all approach, project creators receive however much they collect [9]. The all-ornothing approach is usually considered as less risky for backers, while the keep-it-all approach is less risky from the project creators' viewpoint [17]. For example, Kickstarter follows the all-or-nothing principle, while Indiegogo allows project creators to choose between the two alternatives.

Building on this discussion and previous definitions $[8,37,42]$, we define reward-based crowdfunding as the practice of collecting small amounts of moneyusually to fund creative projects and usually through the Internet-from a large number of people in the form of an open call that follows either the all-ornothing or keep-it-all principle, in exchange for some material or immaterial reward.

\section{Related work}

When crowdfunding initially emerged as a funding practice on the Internet, much of the related research was dedicated to equity-based crowdfunding [10], but reward-based crowdfunding has since increasingly received more attention [32]. Several empirical studies have explored the factors that determine fundraising success [e.g., 22, 30, 31]. Based on the funding principle (i.e., keep-it-all vs. all-or-nothing), success has most often been measured either as the amount of money collected during the funding period [e.g., 51] or as whether the funding goal was reached during that period [e.g., 30].

Most crowdfunding-success research has used the project itself as the unit of analysis, so researchers have often studied fundraising success from the perspective of project design [32]. Crowdfunding websites typically share the same design features [30], so researchers have used similar factors to explain fundraising success. We organize these factors into five broad categories in what follows: project size, project creator, presentation, communication, and rewards (Table 1).

We conceptualize project size as a function of the funding goal and the duration of fundraising. Defining smaller projects, that is, shorter durations and lower funding goals, has usually been found to increase the chances of success [e.g., 30, 37], but there are also contradicting results. For example, Frydrych et al. concluded that funding duration does not have a signifi- 
cant effect on project success [22]. The project creator's social network, measured as his or her number of friends on online social networks, has also been found to influence the success of crowdfunding projects positively [37]. In addition, the creator's own backing history - that is, the number of projects that the project creator has backed - has been found to be significant [54].

Table 1. Selective overview of related work

\begin{tabular}{l|l|l}
\hline Category & Factor & References \\
\hline Project size & Duration & {$[37,52]$} \\
& Funding goal & {$[22,37]$} \\
\hline Project creator & Social network & {$[37,52]$} \\
& Backing history & {$[30,54]$} \\
\hline Presentation & Visualization & {$[30,31]$} \\
& Description & {$[51,53]$} \\
\hline Communication & Updates & {$[37,51]$} \\
& Posts and comments & {$[31,37]$} \\
\hline \multirow{2}{*}{ Rewards } & Number of rewards & {$[31,51]$} \\
& Pricing & {$[26,51]$}
\end{tabular}

Presentation refers to the use of texts, images, and videos to describe and advertise projects. Videos and images have been found to positively influence fundraising success [30, 31], and the depth of the project description has been identified as another success factor [51]. For example, Zhou et al. concluded that the quality of a project's argument is positively associated with fundraising success [53].

On most, if not all, websites, the project description cannot be changed after project launch, so communication like updates, blog posts, and comments, which helps to keep backers and potential backers informed about the project's progress, has been found to influence fundraising success [37, 51]. For example, Kunz et al. provided evidence that the number of blog posts increases the chances of project success [31].

In short, researchers have found a variety of factors that help to explain fundraising success, but the overview of related work we provided represents only a limited account of crowdfunding research. Several other factors that are not directly related to project design have also been studied, including gender and race [e.g., 40]. However, despite the amount of research that has been performed on the factors of crowdfunding success, the most distinctive feature of reward-based crowdfunding - rewards - has seldom been studied. While some researchers have found that the number of rewards influences the chances of fundraising success [e.g., 31], the design of reward menus, including the selection of reward tiers and the donation amounts connected to them, has largely been neglected. Xiao et al. provided first evidence that comparably high-priced rewards positioned at the end of the choice set lead to significantly higher success rates [51], and $\mathrm{Hu}$ et al. argued that, given two product options of similar quality but at different prices, buyers with high product valuations prefer the high-priced option, as long as they perceive that other buyers may have low product valuations [26]. Still, even though researchers have started to explore crowdfunding success from the viewpoint of the reward menu's design, we know little about how rewards, and how they are presented, influence crowdfunding success. As the next section explains, this paper uses theory from behavioral economics to explore how reward menus can be designed to reach funding targets more quickly and make crowdfunding campaigns more successful.

\section{Middle-option bias}

Research in the area of behavioral economics, which is located at the intersection of psychology and economics, deals with decision-making, often at the individual level [15]. Behavioral economists not only explore utility maximization [21], but also how personal attitudes affect decision-making [4] and how deviations from rationality can be explained [27]. To explain the differences between normative and descriptive decision-making (i.e., decisions that do not maximize individual utility), behavioral economists have drawn on the dual-process theory [23], which also provides the conceptual background for the present study.

According to the dual-process theory, decisions are the result of two separate cognitive thinking processes: "System 1" (e.g., unconscious, automatic, quick, and effortless) and "System 2" (e.g., conscious, controlled, slow, and effortful) [20]. Individuals often do not comprehensively search for or thoroughly interpret information because their cognitive capacity is limited and because decision-making can be complex [35] and can require effort [18]. To cope with these limitations, people apply cognitive heuristics and simplified strategies-System-1 processing in the language of the dualprocess theory. For example, people tend to draw on reference points because they provide orientation and make it easy to make decisions quickly [41]; if no references are available, they tend to apply heuristics [48].

The deliberate application of cognitive heuristics and biases by modifying the "choice architecture" [46] —also referred to as "nudging" [29]—allows peoples' behavior to be altered in a predictable way [33]. System-1 thinking is associated with a number of wellknown cognitive biases that can be used to nudge people [33], including the herd effect (i.e., people tend to 
follow the crowd when making decisions) [34], loss aversion (i.e., losses hurt people twice as much as equivalent gains make them feel happy) [28], and status-quo preference (i.e., people are reluctant to change and prefer the current state of affairs) [28].

Another well-known bias is the middle-option bias $[5,16]$, which is in the focus of the present paper. The middle-option bias, which researchers have also called "centrality preference," "edge avoidance," and "the center-stage effect," reflects people's tendency to select "safe" options that are positioned in the middle of a choice set [49]. Researchers have confirmed the robustness of the middle-option bias in several application scenarios, including the process of selecting restroom stalls [16], cereal snack bars [29], and items in supermarkets [16]. However, as several studies have also delivered contradictory findings [6, 19], the validity of the middle-option bias in reward-based crowdfunding remains to be assessed. In this kind of crowdfunding, the middle-option bias may be at play because, from the backers' perspective, crowdfunding can be understood as a problem of choice: given their willingness to support a project financially, they have to decide how much they wish to donate based on the rewards offered. Backers may be prone to the middleoption bias because crowdfunding campaigns often involve innovative and novel products and rewards for which potential backers have only limited or no reference points. Therefore, we hypothesize:

H1: Backers tend to choose the donation option in the middle.

Confirming this hypothesis contributes to theory on how to design and present crowdfunding projects. If reward menus can be designed in a way that backers select the middle option more often than any other, project creators could reach their funding targets more quickly. For example, they could drop low-priced rewards from the reward menu so that higher-priced rewards appear in the middle, allowing them to collect more money from those who select the middle option. This, of course, can only apply under certain conditions; among others, crowdfunding projects are diverse in terms of the number of donation options they offer, and options can vary considerably in price range $[22$, 51]. Therefore, we test two sub-hypotheses:

H1a: Backers tend to choose the donation option in the middle, independent of the price range.

H1b: Backers tend to choose the donation option in the middle, independent of the number of options.

As the next section explains, we tested hypothesis H1a and hypothesis H1b separately in two empirical studies.

\section{Study design}

To test our hypotheses, we conducted an experimental study and an observational study. The experimental study tested the significance of the middleoption bias for donation options with varying price ranges (hypothesis $\mathrm{H} 1 \mathrm{a}$ ), while the observational study tested the same effect for varying numbers of donation options (hypothesis $\mathrm{H} 1 \mathrm{~b}$ ). We recruited participants from prolific.ac, an online crowdsourcing platform for scientific studies, for both studies.

Table 2. Donation options in the two studies

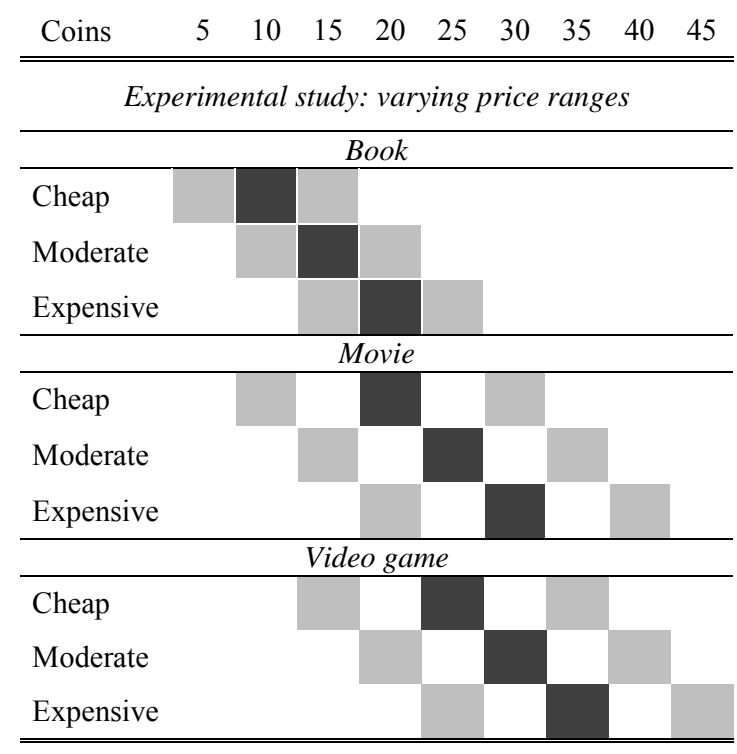

Observational study: varying numbers of options

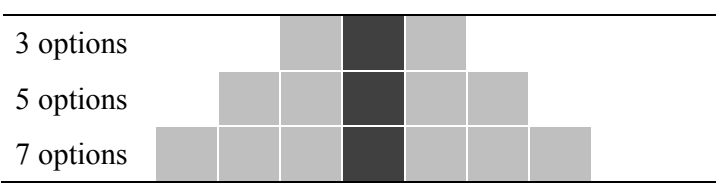

At the beginning of each study, we provided participants with general information concerning tasks and payment, followed by three fictitious crowdfunding scenarios of similar length and structure. The three scenarios featured crowdfunding for a book, a movie, and a video game, respectively, so they represented three of Kickstarter's most common project categories: publishing, film and video, and games. The description of the three projects, for which we used Qualtrics for presentation purposes, was based on several successful Kickstarter campaigns [see 45 for a more detailed description of the three project scenarios]. For each of the three scenarios, participants selected a donation option. Table 2 shows how the donation options were distributed across the three scenarios in the two studies (the middle options are highlighted in dark). 
We defined the studies' currency as "coins," with an exchange rate of 1 coin $=1$ pence. Participants were given 50 coins as a budget for each project. We designed the crowdfunding scenarios as all-or-nothing projects, so participants were told that projects would only be successful if a pre-defined funding goal was reached. (They were not informed about the total amount donated or the number of backers.) In both studies, the book project had a funding goal of 900 coins, the video game a goal of 1,350 coins, and the movie a goal of 1,800 coins. As participants did not self-select into a real-life crowdfunding campaign, there was no opt-out option, so they had to provide funding for all projects with their 50 coins.

Payment was designed to reflect how backers experience project success ("reward") and failure ("loss") in real-life crowdfunding. Therefore, participants received a participation fee of $£ 1$ and variable bonus payments based on their donations to a randomly selected project such that, if that project was successful (i.e., if the sum of all individual donations exceeded the project's funding goal), participants' donated coins were doubled (reward), and if the project was not successful, they lost their coins (loss). For example, if a participant had backed a successful project with 25 coins, and if that project was randomly selected for the bonus payment, his or her bonus payment was 75 pence (50 coins (budget) -25 coins (donation) +50 coins (reward) $=75$ coins).

Finally, participants completed a follow-up survey from which we collected demographic data. We used the statistical software package $R$-in particular, the package multgee for repeated-measures ordered logistic regression modelling - for data analysis [47].

\section{Experimental study: Price range}

Participants and design. We recruited ninety-four participants for the first study, which tested the significance of the middle-option bias for donation options with varying price ranges (i.e., hypothesis H1a). The mean age was 32.1 years, and 61.7 percent were men. The experimental design was repeated-measures single-factorial, and the conditions were three scale types of price ranges - cheap, moderate, and expensive - that differed across projects. (That is, each participant provided funding for each of three projects - repeated measures - in a certain condition.) For example, participants could decide to back the book project with 5,10 , or 15 coins in the cheap-scale condition, with 10,15 , or 20 coins in the moderate-scale condition, and with 15 , 20 , or 25 coins in the expensive-scale condition (Table 2). We randomly assigned participants to the scale conditions. Because of the repeated-measures design, we had 282 observations in total: ninety-four observations in the cheap scale, ninety-six in the moderate scale, and ninety-two in the expensive scale.

Table 3: Decision positions and scale conditions

\begin{tabular}{|c|c|c|c|c|}
\hline \multicolumn{5}{|c|}{ Dependent variable: Decision position } \\
\hline & & 1: First & 2: Middle & 3: Last \\
\hline & & \multicolumn{3}{|c|}{ Book project } \\
\hline \multirow{5}{*}{ 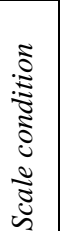 } & 1: Cheap & 5 & 10 & 15 \\
\hline & 2: Moderate & 10 & 15 & 20 \\
\hline & 3: Expensive & 15 & 20 & 25 \\
\hline & & \multicolumn{3}{|c|}{ Movie project } \\
\hline & 1: Cheap & 10 & 20 & 30 \\
\hline$\frac{2}{8}$ & 2: Moderate & 15 & 25 & 35 \\
\hline$\overline{7}$ & 3: Expensive & 20 & 30 & 40 \\
\hline$\tilde{\Xi}$ & & \multicolumn{3}{|c|}{ Video-game project } \\
\hline$\Xi$ & 1: Cheap & 15 & 25 & 35 \\
\hline ถุ & 2: Moderate & 20 & 30 & 40 \\
\hline & 3: Expensive & 25 & 35 & 45 \\
\hline
\end{tabular}

Measurement. For each project, each participant had three donation options to choose from. We defined the dependent variable as the position of the donation option in the choice set (i.e., first, middle, and last). Across all choice sets, the donation options grew more expensive from first to last, so we coded the decision position as an ordinal variable $(1=$ first, $2=$ middle, and 3 = last). The treatment (i.e., the scale condition) was coded as a nominal variable $(1=$ cheap, $2=$ moderate, and 3 = expensive) (Table 3 ). Age and gender were used as control variables.
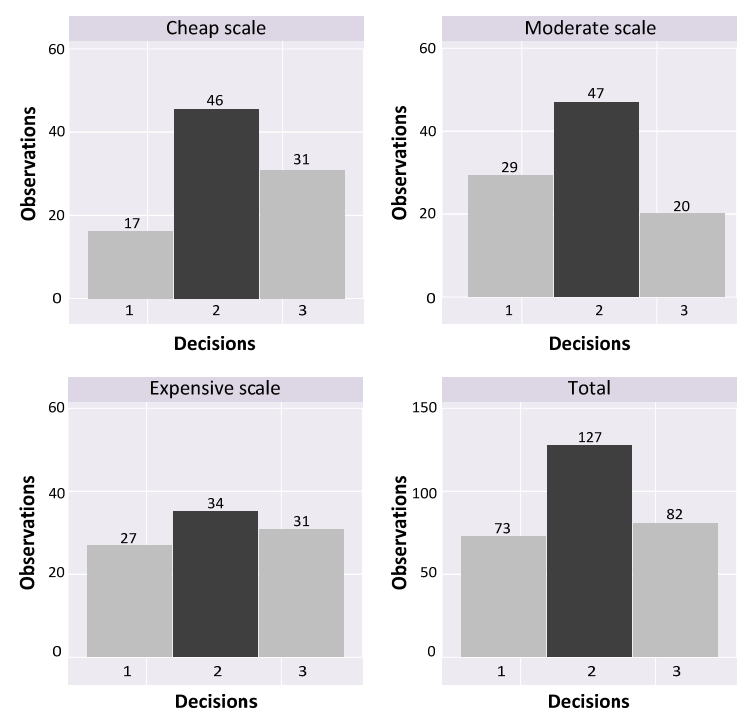

Figure 1. Overview of results across scenarios 
Results. Figure 1 provides histograms for the results of the experiment, aggregated across scenarios. Forty-six of the ninety-four cheap-scale decisions were in the middle, and participants who had either the moderate scale or the expensive scale also tended to choose the middle option more often than other options (forty-seven and thirty-four decisions, respectively). Across all scales, 45 percent of the participants chose the middle option, as opposed to 33 percent, which would have been expected with random selection.

\section{Table 4. Ordered logistic regression results}

\begin{tabular}{llll}
\hline & \multicolumn{3}{c}{$\begin{array}{c}\text { Dependent variable: } \\
\text { Decision position (ordinal) }\end{array}$} \\
& $(1)$ & $(2)$ & $(3)$ \\
\hline Treatment & & 0.14 & 0.15 \\
(scale) & & $(0.15)$ & $(0.15)$ \\
Age & & -0.00 \\
& & $(0.01)$ \\
Gender & & -0.23 \\
& & & $(0.25)$ \\
\hline Intercepts & & \\
$\beta_{01}$ (first $\mid$ mid- & $-1.05^{* * *}$ & $-1.33 * * *$ & $-1.00^{\dagger}$ \\
dle) & $(0.14)$ & $(0.31)$ & $(0.58)$ \\
$\beta_{02}$ (middle $\mid$ & $0.89 * * *$ & $0.62 *$ & $0.95^{\dagger}$ \\
last) & $(0.14)$ & $(0.31)$ & $(0.57)$ \\
\hline Obs. & 282 & 282 & 282 \\
\hline Notes: ${ }^{\dagger} \mathrm{p}<0.1, * \mathrm{p}<.05, * * \mathrm{p}<.01, * * * \mathrm{p}<.001 ;$ \\
standard errors are in parentheses.
\end{tabular}

To test our hypothesis H1a (i.e., backers tend to choose the donation option in the middle, independent of the price range), we specified a repeated-measures ordered logistic regression model. The ordinal multinomial response variable was the decision (i.e., first, middle, last option) in the three scenarios (i.e., book, game, movie project). As we assume that responses are correlated (each participant selected a donation option for each of the three projects), we fitted the following marginal cumulative logit model [47]:

$$
\operatorname{logit}\left(\gamma_{i j p}\right)=\beta_{0 j}+\beta_{1} \text { Scale type }_{i}+\text { Controls }_{i}+\mathrm{u}_{\mathrm{i}}+\varepsilon_{i},
$$

where $\gamma_{i j p}$ denotes the cumulative probability of response level $j$ ( $j=1,2$ for the three decision positions; i.e., level 1 from the first to the middle option, and level 2 from the middle to the last option) for subject $i$ $(i=$ participants $1,2, \ldots, 94)$ and project $p(p=1,2,3$ for the book, game, and movie, respectively). Scale type $_{i}$ denotes the subject-specific treatment (i.e., the scale condition), Controls $s_{i}$ are the control variables Age and Gender, and $u_{i}$ is a random effect designed to capture the non-independence between the decisions (i.e., the outcome variable) observed for the same subject $i$ across the projects $p$ (i.e., observations from the same subject might be correlated).

Table 4 presents the results of the repeatedmeasures ordered logistic regression model. Model 1 is an intercept-only model, Model 2 adds the scalecondition treatment, and Model 3 adds the control variables. To find support for H1a, we expect a significant effect between the first and the middle option and between the middle and the last option $\left(\beta_{01}\right.$ and $\left.\beta_{02}\right)$, but no significant effect of the treatment (i.e., the scale condition). In other words, we expect the selected donation option to be in the middle, independent of the scale. As predicted, $\beta_{01}$ and $\beta_{02}$ are significant across all model specifications, though the significance decreases with higher price ranges (i.e., in Models 2 and 3 ), and the treatment has no significant effect on the decision (Model 2: $\beta_{\text {treatment }}=0.14, \mathrm{p}<0.35$; Model 3: $\beta_{\text {treatment }}=0.15, \mathrm{p}<0.32$ ). As the treatment remains insignificant when we add the controls, we used the simpler Model 2 for further analysis.

Table 5 shows the category probability regarding the outcome variable (i.e., decision $=1,2$, or 3 ) for Model 2. With respect to different treatment conditions, the model estimates that 44 percent would choose the middle option.

Table 5. Category probability (Model 2)

\begin{tabular}{lccc}
\hline & \multicolumn{3}{c}{ Decision position } \\
\hline & 1: First & 2: Middle & 3: Last \\
\hline Cumulative logit & - & -1.33 & 0.62 \\
$\begin{array}{l}\text { Cumulative odds } \\
{[\exp (\text { Cum.logit) }}\end{array}$ & - & 0.26 & 1.85 \\
$\begin{array}{l}\text { Cumulative proportion } \\
{[1 / 1+\exp (\text { Cum.logit) }}\end{array}$ & 1.00 & 0.79 & 0.35 \\
Category probability & 0.21 & 0.44 & 0.35 \\
\hline
\end{tabular}

In conclusion, the experiment's results indicate that people tend to choose the donation option in the middle, independent of the price range.

\section{Observational study: Number of options}

Participants and design. For the second, observational study, which tested the significance of the middle-option bias for varying numbers of donation options (i.e., hypothesis H1b), we recruited another ninety-two participants. The mean age was 31.3 years, and 53.3 percent were men. To test the robustness of the middle-option bias we observed in the first study, we compared three, five, and seven donation options (Table 2). We assigned participants randomly to these conditions. As with the first experiment, each participant selected a donation option for each of the three 
scenarios, resulting in another repeated-measures design. Some participants made their decisions very quickly, which made in unlikely that they have thoroughly read and understood the project descriptions. Therefore, we excluded those decisions from the second dataset that were made within less than fifteen seconds. As a result, we had seventy-nine observations for the three-options condition, eighty for the fiveoptions condition, and seventy-three for the sevenoptions condition.

Table 6: Decision positions and numbers of options

\begin{tabular}{|c|c|c|c|c|c|c|c|c|}
\hline \multicolumn{9}{|c|}{ Dependent variable: Decision position } \\
\hline & & 1 & 2 & 3 & 4 & 5 & 6 & 7 \\
\hline & & \multicolumn{7}{|c|}{ Book project } \\
\hline \multirow{4}{*}{ 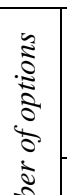 } & 3 options & & & 15 & 20 & 25 & & \\
\hline & 5 options & & 10 & 15 & 20 & 25 & 30 & \\
\hline & 7 options & 5 & 10 & 15 & 20 & 25 & 30 & 35 \\
\hline & & \multicolumn{7}{|c|}{ Movie project } \\
\hline$\stackrel{\xi}{\Sigma}$ & 3 options & & & 15 & 20 & 25 & & \\
\hline 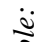 & 5 options & & 10 & 15 & 20 & 25 & 30 & \\
\hline$\cdot \frac{3}{\sqrt[3]{2}}$ & 7 options & 5 & 10 & 15 & 20 & 25 & 30 & 35 \\
\hline$\approx$ & & \multicolumn{7}{|c|}{ Video-game project } \\
\hline : & 3 options & & & 15 & 20 & 25 & & \\
\hline$\frac{\pi}{2}$ & 5 options & & 10 & 15 & 20 & 25 & 30 & \\
\hline 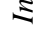 & 7 options & 5 & 10 & 15 & 20 & 25 & 30 & 35 \\
\hline
\end{tabular}

Measurement. While our first study tested the effect of the donation-option scale (e.g., 5/10/15 vs. $10 / 15 / 20$ vs. $15 / 25 / 30$ coins), the second study tested the same effect for varying numbers of donation options. We defined the dependent variable as the position of the donation option in the choice set. (That is, participants had three options to choose from in condition 1, five options in condition 2, and seven options in condition 3; see Table 6.)
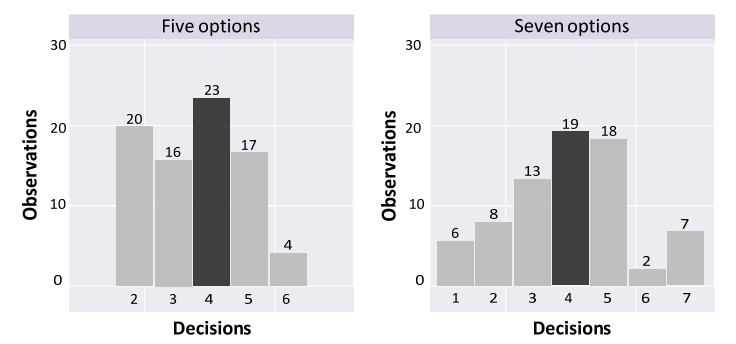

Figure 2. Overview of results across scenarios

For all projects, the three-options scale was $15 / 20 / 25$ coins, the five-options scale was $10 / 15 / 20 / 25 / 30$ coins, and the seven-options scale was 5/10/15/20/25/30/35 coins. Accordingly, the 20-coins option provided the middle option in all scales.
Results. Figure 2 provides histograms for the results of the second study, aggregated across scenarios. For the three-options choice set, thirty-nine out of seventy-nine decisions were in the middle, which confirmed the results of the first study (not displayed in the figure). Participants who had the five-options choice set also tended to choose the middle option, as did participants who had the seven-options choice set (twenty-three and nineteen decisions, respectively).

Table 7. Chi-square test results

\begin{tabular}{lccc}
\hline & Observations & Expected & $\mathrm{p}$ \\
\hline 3 options & 79 & 26.33 & 0.00 \\
5 options & 80 & 16.00 & 0.01 \\
7 options & 73 & 10.43 & 0.00 \\
\hline
\end{tabular}

As the dependent variable was measured on several levels (participants had to select one out of three, five, or seven options), we analyzed each condition separately, making it an observational study. To evaluate the robustness of the middle-option bias with increasing numbers of donation options and to test our hypothesis $\mathrm{H} 1 \mathrm{~b}$ (i.e., backers tend to choose the donation option in the middle, independent of the number of options), we used the chi-square test for univariate frequency distributions. The test determines whether the observed values in each condition differ significantly from an expected value (i.e., the mean of each condition). Table 7 shows the results of the chi-square test, which support our hypothesis that people choose the middle option more often than any other.

Table 8. Log. regression results (intercept-only models)

\begin{tabular}{|c|c|c|c|}
\hline & \multicolumn{3}{|c|}{$\begin{array}{c}\text { Dependent variable: } \\
\text { Decision position (ordinal) }\end{array}$} \\
\hline & 3 options & 5 options & 7 options \\
\hline$\beta_{01}(1 \mid 2)$ & & & $\begin{array}{l}-2.41^{* * *} \\
(0.46)\end{array}$ \\
\hline$\beta_{02}(2 \mid 3)$ & & $\begin{array}{l}-1.10^{* * * *} \\
(0.29)\end{array}$ & $\begin{array}{l}-1.44 * * * \\
(0.30)\end{array}$ \\
\hline$\beta_{03}(3 \mid 4)$ & $\begin{array}{l}-0.66^{*} \\
(0.28)\end{array}$ & $\begin{array}{l}-0.21 \\
(0.21)\end{array}$ & $\begin{array}{l}-0.53 * \\
(0.24)\end{array}$ \\
\hline$\beta_{04}(4 \mid 5)$ & $\begin{array}{l}1.62^{* * *} \\
(0.28)\end{array}$ & $\begin{array}{l}1.03^{* * *} \\
(0.20)\end{array}$ & $\begin{array}{l}0.53^{\dagger} \\
(0.29)\end{array}$ \\
\hline$\beta_{05}(5 \mid 6)$ & & $\begin{array}{l}2.94 * * * \\
(0.61)\end{array}$ & $\begin{array}{l}1.96^{* * *} \\
(0.31)\end{array}$ \\
\hline$\beta_{06}(6 \mid 7)$ & & & $\begin{array}{l}2.24 * * * \\
(0.36)\end{array}$ \\
\hline Obs. & 79 & 80 & 73 \\
\hline
\end{tabular}

For each condition (i.e., 3, 5, and 7 options), we specified a repeated-measures ordered logistic regression model, so the specification was the same as in the 
first study but did not include the treatment variable (i.e., intercept-only models). Again, we assume that responses are correlated, as each participant selected a donation option for each of three projects. Table 8 presents the results of the intercept-only models, particularly the estimated log odds.

As the coefficients shown in Table 8 cannot be interpreted directly, we used the results of the repeatedmeasures ordered logistic regression model to calculate the category probabilities (Table 9), following the same procedure that we used in the first study. Again, all models estimate that people tend to choose the middle option more often than any other.

Table 9. Category probabilities

\begin{tabular}{lrrrrrrr}
\hline & \multicolumn{7}{c}{ Coins } \\
\hline & 5 & 10 & 15 & 20 & 25 & 30 & 35 \\
\hline 3 options & & & 0.34 & 0.49 & 0.16 & & \\
5 options & & 0.25 & 0.20 & 0.29 & 0.21 & 0.05 & \\
7 options & 0.08 & 0.11 & 0.18 & 0.26 & 0.25 & 0.03 & 0.10 \\
\hline
\end{tabular}

In conclusion, the two empirical studies confirmed participants' tendency to choose middle options more often than any other option, independent of both the number of donation options and the price range.

\section{Conclusions}

Crowdfunding is becoming an increasingly important funding mechanism. Still, many campaigns have remained unfunded, even though some of them were promising and failed for other reasons than quality [31]. Against this background, researchers have an interest in how to design and present crowdfunding projects in a way that increases the chances of fundraising success [e.g., 22, 30, 31].

We studied fundraising success from a behavioraleconomics perspective. We drew on dual-process theory, arguing that crowdfunding backers may be prone to System-1 processing-unconscious and quick decision-making [20] that is associated with a number of well-known cognitive biases [48] — as projects and rewards are often novel and innovative and lack appropriate reference points. Specifically, we studied the middle-option bias and hypothesized that-if the reward menu is deliberately designed-backers may choose the donation option in the middle more often than they choose other options. Two empirical studies in a simple, controlled environment confirmed our hypothesis.

Though this is research-in-progress, our preliminary results already have implications for practice. As the results suggest that crowdfunding backers may be prone to the middle-option bias, they can support project creators in designing their reward menus to maximize their chances of meeting their funding targets. For example, they could drop low-priced rewards from the choice set so higher-priced rewards appear in the middle, thereby increasing the size of average donations.

However, project creators should consider that dropping low-tier rewards from the menu may also cause some potential funders to drop out, so they are well-advised to use our results with caution when designing their reward menus. Related studies have suggested that higher numbers of rewards increase the chances of fundraising success [e.g., 31]. In fact, it is likely that the validity of the middle-option bias in reward-based crowdfunding depends on some factors that are outside the scope of this early-stage research.

In particular, the applicability of our results has four primary limitations. First, on most, if not all, platforms, rewards are automatically arranged from cheapest to most expensive, which prohibits the offering from exploiting the full potential of the middle-option bias. Second, it is likely that participants in an online study are more prone to System-1 processing than are actual backers who invest real money (instead of "coins") and receive real rewards in exchange for their donations (instead of small bonus payments). Third, we excluded some important individual-level variables from our study that influence backing behavior, including personal income and preferences regarding projects and rewards. Fourth, we studied the middle-option bias for varying price ranges and numbers of options, but these variations were comparatively small. If the option in the middle of a reward menu has a significantly higher price than the others, it is also likely that the observed effect vanishes. The same may happen when the number of rewards is so high that backers have difficulty finding the middle. In our experiment, for example, the significance of the observed effect decreased with higher prices ranges.

Against this background, our findings provide only preliminary evidence for the middle-option bias in reward-based crowdfunding. However, our early-stage research focused on internal validity by isolating the middle-option bias in a simple, controlled environment. To establish ecological validity, and to provide a more realistic environment, we are developing a mock crowdfunding website that we will use to collect further evidence for the middle-option bias and to test alternative cognitive biases that may influence backers' choices, including the decoy effect [45]. This, we believe, will help us to more holistically understand decision-making in crowdfunding settings and to provide a foundation to further theorize on the design of crowdfunding projects and websites. 


\section{References}

[1] Afuah, A., and C. L. Tucci, "Crowdsourcing as a Solution to Distant Search", Academy of Management Review, 37(3), 2012, pp. 355-375.

[2] Agrawal, A., C. Catalini, and A. Goldfarb, "Some Simple Economics of Crowdfunding", National Bureau of Economic Research, Working Paper 19133, available at: http://www.nber.org/papers/w19133 (retrieved August 30, 2016), 2014.

[3] Ahlers, G. K. C., D. Cumming, C. Günther, and D. Schweizer, "Signaling in Equity Crowdfunding", Entrepreneurship Theory and Practice, 39(4), 2015, pp. 955-980.

[4] Arrow, K. J., and L. Hurwicz, "On the Stability of the Competitive Equilibrium", Econometrica, 26(4), 1958, pp. 522-552.

[5] Attali, Y., and M. Bar-Hillel, "Guess Where: The Position of Correct Answers in Multiple-Choice Test Items as a Psychometric Variable", Journal of Educational Measurement, 40(2), 2015, pp. 109-128.

[6] Bar-Hillel, M., "Position Effects in Choice From Simultaneous Displays: A Conundrum Solved", Perspectives on Psychological Science, 10(4), 2015, pp. 419-433.

[7] Belleflamme, P., T. Lambert, and A. Schwienbacher, "Individual Crowdfunding Practices", Venture Capital, 15(4), 2013, pp. 313-333.

[8] Belleflamme, P., T. Lambert, and A. Schwienbacher, "Crowdfunding: Tapping the Right Crowd", Journal of Business Venturing, 29(5), 2014, pp. 585-609.

[9] Belleflamme, P., N. Omrani, and M. Peitz, "The Economics of Crowdfunding Platforms", Information Economics and Policy, 33, 2015, pp. 11-28.

[10] Bouaiss, K., and I. Maque, "Cartography of Academic Literature on Crowdfunding", available at SSRN:

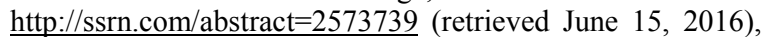
2015.

[11] Bouncken, R. B., M. Komorek, and S. Kraus, "Crowdfunding: The Current State of Research", The International Business \& Economics Research Journal, 14(3), 2015, pp. 407-415.

[12] Bretschneider, U., K. Knaub, and E. Wieck, "Motivations for Crowdfunding: What Drives the Crowd to Invest in Start-Ups?", in: Proceedings of the 22nd European Conference on Information Systems, AIS, Tel Aviv, Israel, 2014.

[13] Burtch, G., A. Ghose, and S. Wattal, "An Empirical Examination of the Antecedents and Consequences of Contribution Patterns in Crowd-Funded Markets", Information Systems Research, 24(3), 2013, pp. 499-519.
[14] Burtch, G., A. Ghose, and S. Wattal, "Cultural Differences and Geography as Determinants of Online Pro-Social Lending”, MIS Quarterly, forthcoming, available at SSRN: http://ssrn.com/abstract=2271298 (retrieved August 30, 2016), 2013.

[15] Camerer, C. F., G. Loewenstein, and M. Rabin (eds.), Advances in Behavioral Economics, Princeton University Press, Princeton, NJ, 2004.

[16] Christenfeld, N., "Choices from Identical Options", Psychological Science, 6(1), 1995, pp. 50-55.

[17] Cumming, D. J., G. Leboeuf, and A. Schwienbacher, "Crowdfunding Models: Keep-It-All vs. All-Or-Nothing", available at SSRN: http://ssrn.com/abstract=2447567 (retrieved June 15, 2016), 2015.

[18] Duhaime, I. M., and C. R. Schwenk, "Conjectures on Cognitive Simplification in Acquisition and Divestment Decision Making", Academy of Management Review, 10(2), 1985, pp. 287-295.

[19] Ert, E., and A. Fleischer, "Mere Position Effect in Booking Hotels Online", Journal of Travel Research, 55(3), 2016, pp. 311-321.

[20] Evans, J. S., "Dual-Processing Accounts of Reasoning, Judgment, and Social Cognition", Annual Review of Psychology, 59, 2008, pp. 255-278.

[21] Friedman, M., and L. J. Savage, "The Utility Analysis of Choices Involving Risk", Journal of Political Economy, 56(4), 1948, pp. 279-304.

[22] Frydrych, D., A. J. Bock, T. Kinder, and B. Koeck, "Exploring Entrepreneurial Legitimacy in Reward-Based Crowdfunding”, Venture Capital, 16(3), 2014, pp. 247-269.

[23] Groves, P. M., and R. F. Thompson, "Habituation: A Dual-Process Theory”, Psychological Review, 77(5), 1970, pp. 419-450.

[24] Haas, P., I. Blohm, and J. M. Leimeister, "An Empirical Taxonomy of Crowdfunding Intermediaries", in: Proceedings of the 35th International Conference on Information Systems, AIS, Auckland, New Zealand, 2014.

[25] Howe, J., "Crowdsourcing: A Definition", available at: http://crowdsourcing.typepad.com/cs/2006/06/crowdsourcing a.html (retrieved August 30, 2016), 2006.

[26] Hu, M., X. Li, and M. Shi, "Product and Pricing Decisions in Crowdfunding", Marketing Science, 34(3), 2015, pp. 331-345.

[27] Kahneman, D., and A. Tversky, "The Psychology of Preferences”, Scientific American, 246, 1982, pp. 160-173.

[28] Kahneman, D., J. L. Knetsch, and R. H. Thaler, "Anomalies: The Endowment Effect, Loss Aversion, and Status Quo 
Bias", The Journal of Economic Perspectives, 5(1), 1991, pp. 193-206.

[29] Keller, C., F. Markert, and T. Bucher, "Nudging Product Choices: The Effect of Position Change on Snack Bar Choice", Food Quality and Preference, 41, 2015, pp. 41-43.

[30] Koch, J.-A., and M. Siering, "Crowdfunding Success Factors: The Characteristics of Successfully Funded Projects on Crowdfunding Platforms", in: Proceedings of the 23rd European Conference on Information Systems, AIS, Münster, Germany, 2015.

[31] Kunz, M. M., O. Englisch, J. Beck, and U. Bretschneider, "Sometimes You Win, Sometimes You Learn: Success Factors in Reward-Based Crowdfunding", in: Proceedings of the 2016 Multikonferenz Wirtschaftsinformatik, Ilmenau, Germany, 2016.

[32] Kuppuswamy, V., and B. L. Bayus, "A Review of Crowdfunding Research and Findings", available at SSRN: http://ssrn.com/abstract=2685739 (retrieved June 15, 2016), 2015.

[33] Leonard, T. C., "Richard H. Thaler, Cass R. Sunstein, Nudge: Improving Decisions about Health, Wealth, and Happiness", Constitutional Political Economy, 19(4), 2008, pp. 356-360.

[34] Lux, T., "Herd Behaviour, Bubbles and Crashes", The Economic Journal, 105(431), 1995, pp. 881-896.

[35] March, J. G., and H. A. Simon, Organizations (2nd ed.), Blackwell Publishers, Cambridge, MA, 1993.

[36] Massolution, "2015CF: The Crowdfunding Industry Report", available at: http://www.crowdsourcing.org/ (retrieved June 15, 2016), 2015.

[37] Mollick, E., "The Dynamics of Crowdfunding: An Exploratory Study", Journal of Business Venturing, 29(1), 2014, pp. 1-16.

[38] Prpić, J., and P. Shukla, "Crowd Science: Measurements, Models, and Methods", in: Proceedings of the 49th Hawaii International Conference on System Sciences, IEEE, Kauai, HI, 2016.

[39] Prpić, J., P. P. Shukla, J. H. Kietzmann, and I. P. McCarthy, "How to Work a Crowd: Developing Crowd Capital Through Crowdsourcing", Business Horizons, 58(1), 2015, pp. 77-85.

[40] Rhue, L., "Who Gets Started on Kickstarter? Demographic Variations in Fundraising Success", in: Proceedings of the 36th International Conference on Information Systems, AIS, Fort Worth, TX, 2015.

[41] Rosch, E., "Cognitive Reference Points", Cognitive Psychology, 7(4), 1975, pp. 532-547.
[42] Schwienbacher, A., and B. Larralde, "Crowdfunding of Entrepreneurial Ventures", in: D. Cumming (ed.), The Oxford Handbook of Entrepreneurial Finance, Oxford University Press, New York, NY, 2012, pp. 369-391.

[43] Star Citizen, "The Stretch Goals", available at: https://robertsspaceindustries.com/funding-goals (retrieved September 22, 2016), 2016.

[44] Surowiecki, J., The Wisdom of Crowds, Random House, New York, NY, 2004.

[45] Tietz, M., A. Simons, M. Weinmann, and J. vom Brocke, "The Decoy Effect in Reward-Based Crowdfunding: Preliminary Results from an Online Experiment", in: Proceedings of the $37 \mathrm{th}$ International Conference on Information Systems, AIS, Dublin, Ireland, 2016.

[46] Thaler, R. H., C. R. Sunstein, and J. P. Balz, "Choice Architecture", in: E. Shafir (ed.), The Behavioral Foundations of Public Policy, Princeton University Press, Princeton, NJ, 2013, pp. 428-439.

[47] Touloumis, A., A. Agresti, and M. Kateri, "GEE for Multinomial Responses Using a Local Odds Ratios Parameterization", Biometrics, 69(3), 2013, pp. 633-640.

[48] Tversky, A., and D. Kahneman, "Judgment Under Uncertainty: Heuristics and Biases”, Science, 185(4157), 1974, pp. 1124-1131.

[49] Valenzuela, A., and P. Raghubir, "Position-Based Beliefs: The Center-Stage Effect", Journal of Consumer Psychology, 19(2), 2009, pp. 185-196.

[50] Wikipedia, "List of Highest Funded Crowdfunding Projects, from Wikipedia, the free encyclopedia", available at https://en.wikipedia.org/wiki/List of highest funded crowdf unding projects (retrieved June 15, 2016), 2016.

[51] Xiao, S., X. Tan, M. Dong, and J. Qi, "How to Design Your Project in the Online Crowdfunding Market? Evidence from Kickstarter", in: Proceedings of the 35th International Conference on Information Systems, AIS, Auckland, New Zealand, 2014.

[52] Zheng, H., D. Li, J. Wu, and Y. Xu, "The Role of Multidimensional Social Capital in Crowdfunding: A Comparative Study in China and US”, Information \& Management, 51(4), 2014, pp. 488-496.

[53] Zhou, M., Q. Du, X. Zhang, Z. Qiao, A. G. Wang, and W. Fan, "Money Talks: A Predictive Model on Crowdfunding Success Using Project Description", in: Proceedings of the 21st Americas Conference on Information Systems, AIS, Puerto Rico, 2015.

[54] Zvilichovsky, D., Y. Inbar, and O. Barzilay, "Playing Both Sides of the Market: Success and Reciprocity on Crowdfunding Platforms", available at SSRN: http://ssrn.com/abstract=2304101 (retrieved June 15, 2016), 2015. 